\title{
Desenvolvimento Local: o caso da comunidade piscatória de São Pedro - Ilha de São Vicente
}

Iolanda da $\mathrm{Cruz}^{1}$

\begin{abstract}
Resumo: O presente ensaio pretende expor a questão do desenvolvimento local, a onde foi analisado como a população local esta inserida no processo de desenvolvimento, e qual o papel de determinados agentes na execução de projectos ou programas de desenvolvimento local. Trata-se de associações local, políticas públicas, Entidades e ONG's que trabalham nessa comunidade piscatória, analisando se existe alguma articulação entre as mesmas na programação e execução de actividades e projectos visando o melhoramento das condições de vida da população local. Uma analise tendo como pano de fundo a comunidade piscatória de São Pedro, na Ilha de São Vicente.
\end{abstract}

Palavras- Chave: Desenvolvimento; População local; ONG, Políticas Públicas.

\section{Local Development: the case of the fishing community of São Pedro -}

\section{São Vicente Island}

\begin{abstract}
This essay intends to expose the issue of local development, where it was analyzed how the local population is inserted in the development process, and the role of certain agents in the execution of local development projects or programs. These are local associations, public policies, entities and NGOs that work in this fishing community, analyzing if there is any articulation between them in the programming and execution of activities and projects aimed at improving the living conditions of the local population. An analysis of the fishing community of São Pedro, on the island of São Vicente.
\end{abstract}

Keywords: Development; Local population; NGOs, Public Policies.

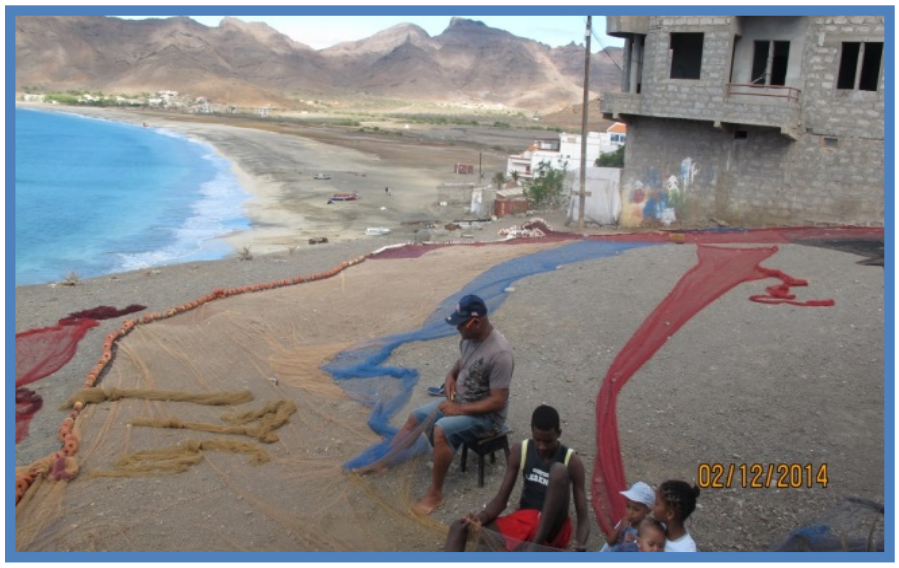

- Enviado em 13/05/2017

- Aprovado em 28/06/2017

\footnotetext{
${ }^{1}$ Licenciada em Ciências Sociais pela Universidade Federal do Paraná (UFPR - Curitiba). Mestre em Ciências Sociais - Tema de pesquisa: Desenvolvimento Local. Parcerias: Universidade de Cabo Verde/UFRGS - Brasil/Science Politique Bordeaux - França. (2012-2014). E-mail: amtchega@hotmail.com
} 


\section{I - INTRODUÇÃO}

O processo de desenvolvimento social, económico e ambiental local, torna-se um diálogo constante entre a comunidade local, as organizações governamentais, as empresas, as escolas e as ONG, como unidades de capacitação, cujo objectivo é o de inserir a população local no processo de desenvolvimento da sua referida localidade. Esta evidente a necessidade da interligação entre o social o económico e o ambiental cuja finalidade é o de se ter um desenvolvimento adequado ou sustentável.

As organizações colectivas nas comunidades piscatórias têm apresentado, em tempos de grandes mudanças de disposição económica, e globalização, como alternativa capaz de responder aos desafios propostos pelo mundo globalizado. Sendo assim, há que se analisar a importância dessas associações locais na vida das comunidades locais, no que tange ao seu contributo ao desenvolvimento local. Assim como analisar a implementação de políticas públicas, direccionadas ao desenvolvimento económico, social e ambiental, na sua actuação nestas comunidades, assim como a participação de ONG estrangeiras ou nacionais, na comunidade referente a execução de algum projecto de desenvolvimento.

\section{Como as populações locais, das comunidades piscatórias, estão inseridas no processo de desenvolvimento social e económico?}

Para responder a pergunta acima, há que se analisar como se processa o desenvolvimento social e económico na comunidade piscatórias/rurais, analisando a intervenção de diversos atores, tais como a associação local, as políticas publicas, as políticas municipais, as Instituições e as ONG que trabalham na comunidade piscatória de São Pedro, na Ilha de São Vicente, verificando se existe alguma articulação entre os mesmos, aliado a participação local, como estratégia de superação da pobreza.

Analisar o real papel do elemento associativista na comunidade litoral, como à alavanca para o desenvolvimento local, assim como a intervenção das políticas públicas governamentais, políticas municipais e ONG que promovem o desenvolvimento na Comunidade local, articulando-as com as acções das organizações locais.

Com a globalização, muitos países, principalmente os países pobres, têm demonstrado dificuldades em conseguir abranger todas as localidades do seu território, devido a uma luta para se sobreviver no mundo globalizado onde o capitalismo traz uma concorrência desenfreada e a globalização em determinados países explora a mão-de-obra local. As sedes das grandes indústrias se situam nos países desenvolvidos e a mão-de-obra explorada nos países menos avançados ou em vias de desenvolvimento. Uma das questões que se pode colocar sobre a globalização é a questão da liberdade de um cidadão de um determinado país participar de forma adequada no desenvolvimento do seu país.

De acordo com Amartya Sen (2001), “o desenvolvimento é um processo das liberdades reais que as pessoas desfrutam" (pag.29). Uma dessas liberdades a que o autor refere é o de participar de forma activa no desenvolvimento do seu país e da própria pessoa para que possa melhorar as suas condições de vida. Trata-se de 
determinantes tais como, disposições sociais e económicas adequadas para que cada indivíduo possa participar activamente no processo de desenvolvimento económico e social do seu país.

No entanto, existem privações de liberdade ao desenvolvimento adequado de um país e do próprio cidadão, nomeadamente a pobreza, a tirania, carência de oportunidades, destruição do sistema social, de entre outros aspectos. Pois, "a despeito de aumento sem precedentes na opulência global, o mundo actual nega liberdades elementares a um grande número de pessoas", senão mesmo a maioria. (Amartya Sem, 2001, pág. 18).

Como liberdades constitutivas da luta pelo desenvolvimento pode-se considerar o de se alimentar bem, gozar de boa saúde, de se vestir ou morar de forma condigna, de ter acesso a água potável, ao saneamento básico e o trabalho. Provavelmente, alguns dos factores que implicam de forma negativa com o direito ao desenvolvimento são a globalização económica, onde a mão-de-obra de países subdesenvolvidos e em vias de desenvolvimento é explorada, falta de capacidade dos governos em aspectos como a produção e os meios financeiros para abranger todo o território com programas de desenvolvimento, ou ainda a corrupção sistémica. Somam-se a estas questões, a ausência de liberdades políticas e civis em regimes autoritários como sejam as restrições impostas à liberdade de se participar na vida social, política e económica da comunidade.

Segundo Amartya Sen (2001), as liberdades denominadas como instrumentais tem a capacidade de ligaremse umas as outras contribuindo com o aumento e o fortalecimento da liberdade humana, que são nomeadamente liberdades políticas, económicas, sociais e segurança protectora. “O que as pessoas conseguem realizar é influenciado por oportunidades económicas, liberdades políticas, poderes sociais e por condições habilitadoras, como boa saúde, educação básica e incentivos e aperfeiçoamento de iniciativas" (pág. 18). Essas liberdades contribuem para o desenvolvimento, sendo crucias para o fortalecimento e expansão das próprias liberdades constitutivas. A falta de capacidade do cidadão para adquirir o básico para que se possa ter uma vida saudável, com qualidade, compromete o desenvolvimento, o que certamente não contribui para a redução da pobreza. A liberdade ou oportunidade económica é uma condição essencial ao desenvolvimento, senão o seu principal meio. As liberdades vão determinar a capacidade de enriquecimento dos cidadãos, evitando a pobreza, a subnutrição e a fome, o analfabetismo e a não participação na vida política.

O desenvolvimento implica matéria-prima (Rostow, 1961), para uma boa produção, no sentido de se reduzir a pobreza, almejando atingir um desenvolvimento sustentável. Tal desenvolvimento pode-se revelar uma questão relativa visto que cada país define seus objectivos e sentido ético específico, o que na verdade diferencia os mais diversos países. Alguns antropólogos, sociólogos e cientistas políticos, como Sousa Santos, Samir Amin, Escobar, vêm o desenvolvimento como uma ideia que o ocidente tenta impor às sociedades e culturas.

No que concerne a Cabo Verde, o país tem conseguido elevar os indicadores de desenvolvimento humano, em relação aos países mais pobres do mundo, tento em consequências alcançado o estatuto de País de Desenvolvimento Médio (PDM). Mas apesar do reconhecimento internacional muitas são as opiniões que não aceitaram a referida mudança de estatuto por acreditarem que ainda Cabo Verde não atingiu um nível de desenvolvimento humano adequado.

Olhando para a comunidade piscatória de São Pedro, questiona-se o desenvolvimento dessa comunidade piscatória através da intervenção de políticas públicas, políticas municipais, Instituições, Agências de desenvolvimento e ONG, 
com programas e projectos de desenvolvimento local executados na comunidade. E em relação a esse desenvolvimento local, fala-se num desenvolvimento de base sustentável, segundo directrizes de algumas instituições activas a nível mundial, como o Banco Mundial, o FMI, Nações Unidas.

Muitos são os intervenientes no processo de desenvolvimento dos países, tais como entidades governamentais, Instituições financeiras, ONG, que conjunta ou individualmente apoiam o referido processo consoante a realidade de cada país. Mas nem sempre o desenvolvimento abarca toda uma população de um país, devido a factores diversos. O desenvolvimento económico, nos mais diversos países, depende do factor produção e das matérias-primas existentes em cada país, determinando assim a evolução do mesmo em termos económicos, sociais e ambientais.

Segundo Rostwo $(1961)^{2}$, o desenvolvimento a nível económico, social e político, tem vindo a desencadear pelo mundo, sendo que cada país apresenta a sua evolução específica, consoante as suas próprias condições. 0 processo de produção, e o bom uso dos recursos naturais, irá determinar o desenvolvimento económico, tendo em conta os processos de produção determinado por cada país. Mas nem sempre o desenvolvimento abarca toda uma população de um país, devido a factores diversos.

Os contornos do desenvolvimento têm vindo a mudar desde a globalização da economia capitalista, o que veio a gerar novas adaptações nos mais diversos países, principalmente nos países ditos subdesenvolvimento ou em vias de desenvolvimento. Alguns conseguiram com sucesso adaptar-se a essa nova realidade, mas muitos infelizmente não, devido, em parte, a concorrência desenfreada do capitalismo, a entrada do FMI, a globalização e até mesmo os conflitos étnico interno em alguns países. Com a globalização, a exploração da mão-de-obra nesses países ditos em vias de desenvolvimento, foi um dos fatores a contribuir para um não desenvolvimento adequado dos mesmos, assim como outros fatores tais como a corrupção sistémica e subornos nas esferas da sociedade civil.

Sendo a globalização um processo transnacional de fluxo de ideias, de tecnologias, e de finanças, o Estado tem actualmente pouca capacidade de controlo económico. Por um lado pode até ser bom se a riqueza for adequadamente distribuída dentro de um país, promovendo assim um desenvolvimento adequado ou sustentável, como muito se fala hoje. Mas muitas são os países que não conseguem acompanhar o desenvolvimento na medida em que são explorados através da mão-de-obra local.

"Si el desarrollo había muerto, que vendría después? En el intento de responder a esta pregunta, algunos empezaron a hablar de una "era de postdesarrollo" (Escobar, 1991)

Ao originar um desenvolvimento desigual, a globalização gera especificidades, sendo uma delas o surgimento do local, geralmente rural ou litoral cujo desenvolvimento requer a intervenção de Associações locais, ONG, Entidades, e Cooperações internacionais.

\footnotetext{
${ }^{2}$ Rostow, W. Etapas do Desenvolvimento Económico, 1961.

${ }^{3}$ Escobar, Arturo (1991) Imaginando un futuro: Pensamiento crítico, desarrollo y movimientos sociales. En Margarita López Maya (ed.), Desarrollo y democracia. Caracas: Universidad Central de Venezuela y UNESCO, pp. 135-170.
} 
“..., la crisis del desarrollo también hace patente que han caducado los campos funcionales com que la modernidad nos había equipado para formular nuestras preocupaciones sociales y políticas relativas a la naturaleza, la sociedad, la economia, el estado y la cultura" (Escobar, A.:) $)^{\prime \prime}$

Além da globalização tornar o mundo mais competitivo a nível económico, verifica-se que as sociedades têm vindo a sofrer diversas transformações, devido ao fenómeno migratório, e verifica-se que os países pobres, cuja mãode-obra muitas vezes é explorada por países industrializados através de dependências que criam nos mesmos, não conseguem fazer face ao liberalismo económico. Surge então a preocupação com o local, de como enquadra-lo na nova conjuntura.

O tema desenvolvimento local tem sido abordado como sendo uma estratégia que considera o desenvolvimento de comunidades específicas, identificadas geograficamente, em zonas rurais ou litorais, por seus recursos e potencialidades. É um tema recente que surgiu após a globalização económica do mundo, por ter sido detectado alguma dificuldades no que consta ao desenvolvimento local. Seria propiciar um desenvolvimento pensando nos recursos locais, criando bases sustentáveis ao desenvolvimento.

Nessa mesma linha, desenvolvimento local, surge como uma versão da teoria de crescimento endógeno, produzido por Frankel (1962). Passou-se a valorizar o capital intelectual como sendo fonte de progresso tecnológico, e é diferente do capital físico e humano, pois enquanto o capital físico e humano são acumulados através da poupança e escolaridade, o capital intelectual cresce através da inovação.

De acordo com Romer (1994), o modelo de crescimento endógeno é produzido no interior do próprio sistema económico, localmente, e não imposto a partir de factores externos, como é o caso dos modelos neoclássicos tradicionais. É um crescimento que vai integrar-se na conjuntura, para que o local não fique isolado economicamente, ou seja, vai buscar formas de integrar o local e os processos globais num esforço para impedir que nos tornemos "simples consumidores de modelos culturais elaborados pelos mercados" (Touraine, 1997).

De acordo com Long e Van der Ploeg (1994), o desenvolvimento endógeno constrói-se sobre os recursos localmente disponíveis, destacando-se, de entre outros aspectos, a força de trabalho, as potencialidades ecológicas locais, conhecimentos e modelos locais para articular produção e consumo, e tem características socioculturais, e económicas locais, que se relacionam entre si promovendo o desenvolvimento local.

Por seu turno, Sandroni (1994) já considera desenvolvimento económico como crescimento (incrementos positivos no produto) acompanhado por melhorias do nível de vida dos cidadãos e por alterações estruturais na economia. Defende que o desenvolvimento depende das características de cada país ou região, como sejam a sua história, a posição geoestratégica, da extensão geográficas, das condições demográficas, da cultura e dos recursos naturais endógeno. ${ }^{5}$

\footnotetext{
${ }^{4}$ Escobar, Arturo (1991) Anthropology and the Development Encounter: The making and marketing of Development Anthropology.

${ }^{5}$ Oliveira, Gilson. Revista FAE, Curitiba, v.5, n.2, p.37-48, Maio/Agosto. 2002
} 
Referente à participação da população na tomada de decisões, nota-se, actualmente, a valorização da participação nas mais diversas actividades direccionadas ao desenvolvimento, nas mais diversas esferas, na medida em que essa participação caracteriza-se, ou precisa-se dela para se caracterizar o regime democrático. Nesse sentido, para que o processo de desenvolvimento tenha resultados reais e sustentáveis, requer a participação do cidadão a nível de criação dos objectivos e na sua execução.

A participação social e política da sociedade civil obriga o Estado a ser mais rigoroso na prestação de contas e aumenta os poderes dos cidadãos para gerir os próprios assuntos. (Friedman. 1996, apud Challinor. Ano. P.97.115)

"A empatia lubrifica a sociabilidade, e nós, os seres humanos, somos animais sociais por excelência." (GOLEMAN, Daniel (2006).

Ao surgir a associação local, ela necessariamente ira precisar de parceiros para criar condições e promover o desenvolvimento na comunidade, identificando necessidades, elaborando projectos e procurando financiamento. E são muitas as organizações não- governamentais nacionais e internacionais, entidades e organismos disposto a trabalhar nesse sentido.

Logicamente, para que esses grupos funcionem os respectivos representantes tem que estar capacitados da melhor forma possível, de modo a melhor gerirem a organização. Geralmente nas comunidades, juntamente com as associações locais, as ONG destacam-se como as maiores parceiras de desenvolvimento local.

De acordo com Julie Hearn (2007, pág. 1095), "The term non-governmental organization (NGO) has become an established part of the development lexicon. NGOs are commonly understood to be voluntary, not-for-profit organizations, independent of government and business (Michael, 2004). In reality the boundaries are blurred. Given the close working relationship with both Northern and Southern states, the extent to which NGOs are 'nongovernmental' is a source of much debate. Here I am concerned with NGOs involved in development work in African countries. I will use two distinctions: the first is between Northern and African NGOs; the second is between NGOs as intermediary service provision organizations that are set up for public benefit, and membership organizations that exist for mutual benefit, often known as community-based organizations (CBOs). As NGOs and CBOs work increasingly closely together in foreign-funded programmes, the distinction between the two has become less clear. Finally, other African civil society organizations (CSOs), such as think tanks and advocacy groups, have been picked up by the donor radar to play a key role in international development policy. Although focusing on African intermediary service provision NGOs, the dynamic explored in this article applies to the increasing range of Northern-funded African nonstate actors."

As ONG são tidas como as grandes parceiras do desenvolvimento local, por envolverem directamente com a população local, através das associações comunitárias, tendo como finalidade promover o desenvolvimento dos que carecem de meios para o fazer, assim como criar uma certa estabilidade e sustentabilidade na comunidade.

Essas ONG já movimentaram e ainda movimentam milhões através das ajudas externas que recebem para a execução de projectos. (1990 2003, Hearn. 2007) 
Segundo alguns autores (Challinor, Friedman,1996...) quando bem organizadas e funcionais, a existência de associações comunitárias nas pequenas comunidades rurais e litorais, trazem benefícios para o desenvolvimento local, na medida em que para se fazer face a concorrência dos mercados globais, somente a união dos que menos posses têm, poderá garantir um desenvolvimento adequado nessas referidas localidades. As mesmas poderão representar uma mais-valia para a comunidade local, dependendo do interesse dos que criam a associação, visto que pode também ser uma associação criada para o interesse de um grupo bem restrito que quererá tirar proveito próprio em detrimento da população da localidade. Algo que se pode constatar analisando o percurso de uma associação no terreno.

Referente ás políticas públicas, elas podem ser influenciadas pelo uso efectivo das capacidades participativas das pessoas, verificando-se também que essas mesmas capacidades podem ser aumentadas pelas políticas públicas. Existe hoje uma necessidade da união de sinergias entre as esferas políticas, económicas e sociais, visando um desenvolvimento integrado, através de políticas públicas de desenvolvimento, que dêem oportunidades a todos os cidadãos e/ou a toda a população.

Nesse sentido, actualmente nota-se que os promotores dos projectos, requerem a participação da população local, o que se concretiza através das associações comunitárias.

"Tornou-se politicamente correto incluir a participação nas políticas de cooperação, na elaboração dos projectos e programas." Friedman, John (1996) ${ }^{6}$

O próprio governo elabora uma série de políticas públicas, sociais e económicas, que constituem pilares para que as localidades litorais e rurais se desenvolvam a nível social, económico e ambiental. Geralmente os projectos e os programas são executados em articulação com a associação local, o que implica a participação da população local no processo de desenvolvimento da sua comunidade.

De acordo com Gentilli, (2007, p. 77-78) “...toda política pública é uma acção estatal, uma vez que sua formulação, incentivo e recursos são patrocinados pelo Estado. É óbvio que o Estado pode delegar uma ou outra acção a terceiros, isso, claro, desde que consentida pela norma jurídica, pelo interesse público, necessidade colectiva sem ingenuidades." (Welling "Expressão tradicionalmente consagrada como referente a acções governamentais dos Estados modernos tendo em vista atender a redução das consequências da pobreza em diversas áreas de serviços, como educação, saúde, habitação, previdência etc. Essas acções visam equacionar, em alguns casos, ou minimizar, em outros. $^{\prime \prime 8}$

\footnotetext{
${ }^{6}$ CHALLINOR, Elizabeth Pilar. O Silencio e as Palavras: Reflexões à volta da Participação e do Poder na promoção do Associativismo em Cabo Verde. 1996)
}

${ }^{7}$ Wellington Trotta. POLÍTICA SOCIAL: PERSPECTIVA DE MEDIDAS EFETIVAMENTE PÚBLICAS

${ }^{8}$ GENTILLI, Raquel. Representações e práticas. SP: Veras, 2006. 
Essas políticas sociais tem como finalidade minorar os efeitos das políticas de mercado no mundo do trabalho, isso porque "a política social se constituiu e se desenvolveu no bojo do atendimento a necessidades sociais decorrentes das dinâmicas de expansão quanto das de recessão industrial” (Gentilli, 2007, p. 78).

Nesse sentido entende-se que as políticas sociais constituem programas sociopolíticos, que regulamentam as relações entre Estado e sociedade no que concerne ao processo de reprodução social do mercado de trabalho. De acordo com Gentilli (2006) ${ }^{9}$, as políticas sociais não só são frutos de lutas organizadas pelos grupos de pressão, como decorrem de estruturas culturais, visto que cada formação social, embora coberta pela produção capitalista, guarda suas peculiaridades segundo os aspectos históricos desenvolvidos. Assim todos os países engendram mecanismos próprios, visando solucionar seus problemas sociais.

De acordo com Buarque (1999), "O desenvolvimento local dentro da globalização é uma resultante directa da capacidade dos atores e da sociedade locais se estruturarem e se mobilizarem, com base nas suas potencialidades e sua matriz cultural, para definir e explorar suas prioridades e especificidades, buscando a competitividade num contexto de rápidas e profundas transformações. No novo paradigma de desenvolvimento, isto significa, antes de tudo, a capacidade de ampliação da massa crítica de recursos humanos, domínio do conhecimento e da informação, elementos centrais da competitividade sistémica."

\section{II - DESENVOLVIMENTO}

\section{II - 1. Comunidade piscatória de São Pedro - Ilha de São Vicente}

São Pedro é, por excelência, uma pequena comunidade piscatória da ilha de São Vicente, pertencente à freguesia de Nossa Senhora da Luz, e fica a cerca de $7 \mathrm{~km}$ a sudoeste da cidade do Mindelo. A nordeste da comunidade litoral localiza-se o aeroporto Internacional da ilha. No extremo oposto da comunidade, a oeste, no lugar de Santo André, encontra-se uma moderna unidade hoteleira, com pequenos apartamentos. É o único hotel turístico em funcionamento e próximo da comunidade. A $2 \mathrm{~km}$, mais para oeste, fica o farol de Dona Amélia que poderá ser uma atracção turística se for reabilitado. ${ }^{10} \mathrm{~A}$ paisagem da localidade é árida, mas possui uma praia internacionalmente apreciada para a prática do windsurf, proporcionado pelos ventos constantes.

A população de São Pedro está estimada em cerca de 991 mil habitantes (INE 2010), sendo 513 do sexo masculino e 478 do sexo feminino. Sendo uma comunidade habitada essencialmente por pescadores, a maioria da população vive dos rendimentos provenientes da pesca, verificando-se assim uma economia dependente da referida actividade, uma situação que há muito perdura.

Referente a cultura, temos nessa comunidade piscatória a festa de São Pedro, festa religiosa, festejada pelos pescadores e a população em geral.

\footnotetext{
${ }^{9}$ (ver nota 8)

10 Cruz, Iolanda. Políticas de Desenvolvimento, ONG, Participação e Desenvolvimento Local: estratégias articuladas para o desenvolvimento da comunidade piscatória de São Pedro. (2012-2014)
} 
Em relação as infra-estruturas existentes na comunidade, destacamos uma escola do Ensino Básico Integrado (em que se lecciona da 1a a 6a classe), e uma unidade sanitária de base e infra-estruturas deficientes de saneamento básico, água e esgoto. Também há na comunidade um Jardim infantil.

A unidade sanitária de base segundo informação dos moradores existe desde 1976, tem um servente/enfermeiro que presta os primeiros socorros à população. A ambulância do aeroporto Internacional de São Vicente, quando disponível, apoia a comunidade no transporte de doentes para o hospital da cidade. Uma vez por semana a comunidade conta com a visita de um médico. Na comunidade não existe uma farmácia, o que consta das reivindicações dos moradores locais.

É uma comunidade que tem trabalhado com ONG nacionais e internacionais, e ainda carece de políticas municipais e de políticas públicas de desenvolvimento local, como podemos ver adiante na análise dos indicadores de desenvolvimento local.

\section{O quotidiano local}

A vida na comunidade começa bem cedo, quando canta o galo. As 7h:30 da manhã lá vão da crianças apanhar os transportes públicos para se deslocarem a escola na cidade do Mindelo. A escola em São Pedro vai até a 6ạ classe. Após isso, deslocam-se a cidade do Mindelo, que fica a sete quilómetros, para prosseguir com os estudos.

Também os pescadores arrastam seus botes artesanais para o mar, para mais um dia de trabalho em benefício da família e da comunidade. Alguns começam a faina ainda de madrugada e terminam ao amanhecer ou no período da tarde, outros vão já com o sol a nascer e terminam ainda no período da manhã, e outros vão a meio do período da tarde e regressão no dia seguinte de manhã. Após a faina no mar, lá vão as vendedoras de peixe levar o produto para o mercado na cidade do Mindelo, em pic-up de caixa aberta, chamadas na língua crioula de "juvitas" de caixa aberta, e a maioria delas são esposas dos pescadores. E também são domésticas, trabalham em casa ou na casa de outra, cuidando da casa, dos filhos, do marido, da limpeza da casa.

Existe uma diferença entre as vendedeiras de peixe de São Pedro e os da cidade do Mindelo que se situam no mercado de peixe. Essas mulheres de São Pedro vão concluir o trabalho iniciado pelos pescadores, que geralmente são seus respectivos maridos, que é o de levar o peixe para o mercado do Mindelo, vende-lo as vendedoras do referido mercado e regressam de imediato a São Pedro. As do mercado, sim, vendem o peixe no mercado a população, e também nas ruas de forma ambulante. Na verdade as mulheres de São Pedro vão levar o peixe ao mercado da cidade para ser vendido a população pelas vendedoras de peixe que ai trabalham. Ajudam os pescadores a concluírem a faina.

A construção da identidade do pescador artesanal é um processo que liga o conhecimento e o trabalho. Inicia-se na maioria das vezes logo nos primeiros anos de vida, ou seja, mais ou menos por volta dos 10 anos de idade, onde os meninos começam a se interessar pela pesca, ajudando nas actividades mais simples, como separar o pescado, desenrolar as redes, ajudar no arrasto dos botes, etc. Sejam eles filhos, netos, sobrinhos ou mesmo vizinhos dos pescadores, acompanham os mais velhos até a praia, para observá-los durante a saída e chegada do mar. 
As poucas mercearias na comunidade abrem as portas entre as $8 \mathrm{~h}: 30$ - 9h:00, mas se alguém não abrir isso não é problema. Chama-se gentilmente na porta da casa do dono da mercearia solicitando algo de que se precisa. Nota-se aqui uma solidariedade entre as pessoas da comunidade, ajudando umas as outras, parentes ou não, o que já não acontece com frequência na cidade, ou seja, melhor analisando, a solidariedade local é maior do que numa cidade. Também abrem-se as portas das associações locais para iniciarem o dia de trabalho, assim como a Comissão da Câmara Municipal de São Vicente ai instalada para trabalhar na comunidade.

No final da tarde, os pescadores e outros homens da comunidade se encontram numa pracinha para jogar bisca, e conversar sobre o seu dia, assim como as mulheres sentam-se na porta de casa a conversar sobre seu dia.

\section{Diário de Campo - parte I}

Como começar a narrar o primeiro impacto de contacto com a comunidade no âmbito deste estudo, (?). Pensei eu, antes de ir ao terreno, que não ia ser difícil estabelecer um diálogo com as pessoas na comunidade de São Pedro, na medida em que já trabalho nessa comunidade através da Instituição a onde trabalho. Só ainda não me tinha dado conta que a comunidade se ressentia de algum assunto pendente por parte da Instituição a onde trabalho, ou de outras entidades e instituições do sector das pescas em geral. E isso fez com que a minha pesquisa encontra-se pela frente alguma dificuldade em se realizar, de início.

No meu caso não é bem um "estranhamento" como já visto por Frans Boas e Bronislaw Malinowski, por exemplo, na medida em que a minha pessoa não é totalmente estranha na comunidade de São Pedro, mas talvez possa dizer uma certa desconfiança em relação a mim, se estou a fazer um trabalho pessoal ou se estou a fazer um trabalho ligado a instituição a onde trabalho. É uma sensação de como se eu estive a meter-me na vida deles, no quotidiano das pessoas que ali vivem.

Malinovski, na sua obra Argonautas do Pacífico Ocidental publicada pela primeira vez em 1922, disse o seguinte: "Imagine o leitor que, de repente, desembarca sozinho numa praia tropical, perto de uma aldeia nativa, rodeado pelo seu material, enquanto a lancha ou pequena baleeira que o trouxe navega até desaparecer de vista. Uma vez que se instalou na vizinhança de um homem branco, comerciante ou missionário, não tem nada a fazer senão começar imediatamente o seu trabalho etnográfico. Imagine ainda que é um principiante sem experiência anterior, sem nada para o guiar e ninguém para o ajudar, pois o homem branco está temporariamente ausente, ou então impossibilitado ou sem interesse em perder tempo consigo. Isto descreve exactamente a minha primeira iniciação no trabalho de campo na costa Sul da Nova Guiné." (Bronislaw Malinovski, parte III)

Eu, ao contrário de Malinovski, como já havia dito anteriormente, não era totalmente estranha na comunidade, mas mesmo assim ao tentar estabelecer um diálogo, expondo os meus objectivos de ali estar com eles, sempre me diziam: "ah, mas a senhora já sabe de tudo, não precisa da nossa resposta"; ou então: "vocês fazem tantos estudos e diagnósticos na nossa comunidade, e depois não divulgam os resultados para o nosso conhecimento". Ou simplesmente evitam a minha aproximação e diálogo comigo.

A minha relação ou interesse pelo tema dessa pesquisa, é ver e sentir de perto o que realmente acontece no processo de desenvolvimento local, na medida em que verifiquei algumas falhas ou algo parecido, de comunicação 
entre a associação local e alguns parceiros de desenvolvimento, e também no funcionamento da associação local que é quase que totalmente dependente de outros parceiros, sejam eles ONG nacionais e internacionais, Organismos, Instituições. Analisar o empenho da associação local em criar condições para promover o desenvolvimento local.

Também alargar o meu conhecimento, aprofunda-lo em relação ao quotidiano dessa comunidade essencialmente de pescadores. O valor da pesca para essa comunidade e sua gente. Segundo Ruth Benedict (s/d, p. 15), a história da vida individual de cada pessoa é acima de tudo uma acomodação aos padrões de forma e de medida tradicionalmente transmitidos na sua comunidade de geração para geração. Desde que o individuo vem ao mundo os costumes do ambiente em que nasceu moldam a sua experiencia dos factos e a sua conduta. Quando começa a falar ele é o frutosinho da sua cultura, e quando crescido e capaz de tomar parte nas actividades desta, os hábitos dela são os seus hábitos, as crenças dela as suas crenças, as incapacidades dela as suas incapacidades."

\section{Diário de campo - parte II}

Numa tarde, um pouco ventosa, sentei-me no chão ao lado de algumas pessoas cuja idade variava entre os 25 e os 75 anos. Eram cerca de cinco pessoas. Iniciei um diálogo como quem não quer nada. Cumprimentei, e em seguida fiz-me de perdida com uma certa conversa que me ocorreu na cabeça, quando não encontrei aberta a porta da associação de pescadores de São Pedro. Comecei um diálogo perguntando o que achavam do desenvolvimento de São Pedro; a comunidade desenvolveu nos últimos 25 anos e em que medida. Devo salientar que a conversa foi toda em crioulo a língua que falamos no dia-a-dia.

Uma senhora, a dona Maria de 70 anos, sentada numa pedra com a sua bengala na mão, ao meu lado, começou a falar: "Antigamente a lenha aqui em minha casa estava sempre acesa; tínhamos peixe em abundancia. $O$ pescador pescava aqui mesmo na baia e nós os víamos. Mas agora a baia não tem mais peixe. Agora vão mais longe, não os vemos, e não trazem quase nada de peixe. Uma tristeza. Mas ainda acendo o meu fogão a lenha; ainda cozinho a lenha."

Logo em seguida entra no diálogo um pescador antigo, o Senhor José, com seus 68 anos: “Antigamente tínhamos peixe aqui perto na terra, nessa nossa baia; mas hoje ... nem por isso. O peixe é o sustento dessa comunidade". Mudando da pesca passa a falar da segurança na comunidade: "As coisas por aqui estão a mudar em relação a segurança das pessoas. Vem indivíduos da cidade fazer arruaça aqui em São Pedro e não temos um posto policial. Precisamos urgente de um posto policial".

Uma outra senhora, de nome Teresa, 42 anos, entrou no diálogo, e começou por dizer: "que São Pedro não tem nada; não temos nem uma padaria. E a unidade sanitária de base tem um servente/enfermeiro que muito pouco faz; faz apenas curativos básicos. Se precisarmos de um médico, temos que deslocar a cidade do Mindelo. O médico vem a comunidade de quinze em quinze dias; o PMI-PF vem uma vez por mês para vacinar e consultar as crianças. Muitas das pessoas da comunidade vão trabalhar na cidade e isso é um custo. Para o turista só temos um restaurante cujo dono é um estrangeiro e é abastecido por uma senhora de São Pedro". 


\section{Diário de Campo - parte III}

Dia extremamente ventoso em São Pedro, e poucos são os botes de pesca artesanal que saíram para a faina. Aproximei-me de um idoso dos seus 90 anos que sentado na porta da sua casa observava o mar com uma aparência de preocupado. Aproximei-me, cumprimentei-o e comecei um diálogo. Ao lhe perguntar o porquê de estar a observar o mar, imediatamente respondeu, "antigamente na praia, aos nossos pés apanhávamos peixe até com a mão, mas hoje, os botes tem que ir tão longe, a que já não os vemos. E é um perigo para os pescadores artesanais. E para complicar sendo o peixe o sustento da comunidade, se continuarmos assim vamos ter sérios problemas, como o da fome por exemplo".

Mudando de assunto ele começou a falar do sossego que tinha antigamente na comunidade. "Hoje precisamos urgente de um posto policial na comunidade, porque vem pessoas da cidade do Mindelo fazer arruaça por aqui. E quando se chama a polícia até chegarem em São Pedro as pessoas que vieram fazer arruaça já não se encontram por aqui."

Mais a frente, encontrei a porta de uma mercearia três senhores, com idade compreendida entre os 38 e os 45 anos, também com um ar desanimado observando o mar. "Bom dia, hoje a mercearia esta com pouco movimento?" "Oh sim minha senhora, quando não há peixe não tem dinheiro para se gastar noutras coisas. A pesca não esta nada boa. Antigamente os pescadores de São Pedro é que abasteciam o Mercado de peixe da cidade do Mindelo." E já estamos cansados de promessas que muitos têm feito para São Pedro."

"Os turistas estrangeiros que vem a praia de São Pedro não compram nada na comunidade; as vezes só uma garrafa de água." Talvez porque ainda não temos apoio no que se refere ao empreendedorismo; os jovens e muita gente carecem de formação. Até o pão vem da cidade."

Aos poucos, vou ficando a ser mais familiar na comunidade, e as pessoas demonstram isso ao me cumprimentar com simpatia e um sorriso terno nos lábios.

\section{Diário de campo - parte IV}

E lá cheguei eu mais uma vez na comunidade de São Pedro. Recebida pela população, com comprimentos sorridentes demonstrando simpatia, ou seja, já posso estar a vontade para circular e conversar. Já sou conhecida na comunidade. Também constatei que finalmente já abriram a primeira padaria na comunidade de São Pedro. Segundo informações a padaria foi aberta no mês de Março de 2014, por um jovem casal de São Pedro em parceria com a Agencia para o Desenvolvimento Empresarial e Inovação (ADEI), no projecto Cria. O casal empregou três jovens da comunidade e funciona numa casa alugada, com alguns equipamentos de produção como forno, batedeira e estufa. E lá continuei a minha caminhada observando e as vezes como quem não quer nada, fazendo uma perguntinha ali outra acolá. Algumas pessoas aproximam querendo dialogar comigo a cerca do meu trabalho. 


\title{
III-2. Politicas Públicas de Desenvolvimento Local em Cabo Verde
}

No programa do governo de Cabo Verde para a VIII Legislatura 2011-2016, foram identificadas algumas políticas públicas direccionadas as pequenas comunidades rurais e litorais.

\begin{abstract}
"A nossa visão é uma nação inclusiva, justa e próspera, com oportunidades para todos. O objectivo da VIII legislatura é construir uma economia dinâmica, competitiva e inovadora, com prosperidade partilhada por todos. Para isso, impõe-se acelerar o ritmo da transformação da economia e de modernização da sociedade. Todas as acções serão direccionadas para esta visão e para a construção de um futuro melhor para os CaboVerdianos, tanto em Cabo Verde como na Diáspora." (Programa do Governo para a VIII Legislatura; $2011-2016)^{11}$
\end{abstract}

Segundo a citação acima descrito no Programa do Governo para a VIII Legislatura, 2011 - 2016, pretende-se um desenvolvimento direccionamento para todos os sectores e toda a sociedade cabo-verdiana através de uma economia dinâmica, competitiva e inovadora tendo como meta um desenvolvimento adequado para todos.

Cabo Verde é um país que depende muito da importação de quase tudo, como alimentos, vestuário, calçado, entre outros. Não tem uma produção capaz de assegurar um equilíbrio entre importações e exportações. Nesse sentido torna-se um país que sente a crise mundial, de forma bem acentuada, com o aumento do preço das necessidades básicas. Como já se havia mencionado anteriormente, promovendo o alargamento da bases produtivas, criar condições para a produção, o país poderá fazer face a economia capitalista e globalizada. Mas é algo que requer avultados investimentos monetários (financeiros), o que deverá vir de fora do país. Nesse sentido, sendo que Cabo Verde é um país que tem demonstrado estabilidade política, e reconhecimento por partes dos Países desenvolvidos, poderá sim adquirir algum investimento por parte dos mesmos.

"Igualmente importante durante a VIII legislatura serão os programas de integração das áreas rurais no processo de transformação. Duas ideias fundamentais serão implementadas: o empoderamento dos pobres e o dos que vivem nas zonas rurais, para aumentarem a sua capacidade produtiva. Aqui se incluem programas para facilitar a capacitação, para promover o acesso a recursos financeiros e às infra-estruturas e serviços sociais. Serão desenvolvidos programas específicos para ligar as áreas rurais ao sector do turismo através da cadeia de valor e para promover o turismo rural e ecológico. A expansão do turismo às áreas rurais será feito através da promoção de linkages com as políticas e programas de habitação, permitindo aos pobres e aos habitantes das zonas rurais participar no turismo e noutros sectores da economia." (Programa do Governo para a VIII Legislatura; 2011 - 2016)

Muitos projectos apresentados para serem executados nas comunidades rurais e litorais, justificam-se com a palavra empoderamento, mas ao fim do projecto vesse muitas dificuldades por parte da população local em gerir o que ficou na comunidade, ou seja, o resultado do projecto, devido a uma não adequada capacitação para tal. Ou

\footnotetext{
11 Programa do Governo para a VIII Legislatura; 2011 - 2016.
} 
mesmo um não seguimento ou uma não assistência técnica após a execução do projecto, para que a população possa gerir bem o resultado do projecto implementado na comunidade.

“O Empoderamento/Formação será outro eixo da acção do Governo. Cerca de 4.000 pessoas/ano serão formadas para chefia de exploração, com prioridade para os jovens e as mulheres do meio rural. Serão também formados mais de 4.000 profissionais para assistirem às novas áreas irrigadas. A massificação dos centros de processamento agrícola como estratégia para o reforço da cadeia de valores na agricultura reforçará a actividade do agronegócio. O nosso objectivo é alargar a economia rural, melhorar a capacidade de todos (incluindo os pobres) para participar na economia produtiva e criar milhares de postos de trabalho no mundo rural." (Programa do Governo para a VIII Legislatura; 2011 2016)

Esta também patente no programa do governo, a capacitação e/ou a formação, algo primordial para que uma sociedade se desenvolva a todos os níveis. A educação representa um dos grandes pilares de desenvolvimento de um País, na medida em que privilegiando a formação profissional do seu cidadão vai contribuir para o desenvolvimento social, económico e ambiental.

\begin{abstract}
"Alguns dos maiores êxitos da nação, durante a última década, têm a ver com a redução significativa do número de pobres e a expansão do acesso aos serviços sociais. $\mathrm{O}$ acesso a serviços, tais como cuidados médicos, ensino, electricidade, água potável e estradas aumentou significativamente. De igual modo, a pensão social mínima foi aumentada, o sistema de protecção social foi alargado e reformou-se o sistema de pensões."
\end{abstract}

Em Cabo Verde ainda muitas das comunidades rurais e litorais, não tem saneamento básico, em termos de esgoto e água canalizada nas respectivas casas. Assim como os postos de saúde e unidades sanitárias de base nas comunidades, ainda por melhor ser implementado e apetrechadas. Muitos dos postos de saúde e unidades sanitárias de base, tem apenas um enfermeiro permanente, e outros abrem de quinze em quinze dias, e as vezes uma vez por mês quando a comunidade rural ou piscatória é de difícil acesso. As políticas públicas incluem essa vertente, saneamento básico, mas ainda muito tem que ser feito para superar essas necessidades das pequenas comunidades rurais/litorais. Em São Pedro existe uma Unidade Sanitária de Base que tem um servente/enfermeiro que atende os ferimentos para curativo e aplicar injecções. Se o caso for grave, a pessoa terá que se deslocar a cidade do Mindelo que fica a cerca de $7 \mathrm{Km}$ de São Pedro. E ainda não existe na comunidade uma rede de esgotos. Políticas públicas ainda por serem melhor implementadas no terreno, sendo que a criação de condições para o desenvolvimento local destaca-se no programa do Governo, projectada por uma visão de desenvolvimento que promete abranger todos os sectores da sociedades, assim como todas as localidades e/ou zonas do País.

"As áreas rurais serão um beneficiário-chave. Para além da extensão de serviços sociais e da promoção da ligação dos agregados familiares aos serviços básicos, trabalharemos activamente no desenvolvimento e implementação de um programa de desenvolvimento rural. O objectivo será o empoderamento da população rural e da camada mais vulnerável 
da população, especialmente as mulheres e a juventude, de forma a melhorar as suas habilidades e capacidade produtivas, aumentar a sua participação na economia e melhorar os seus rendimentos." (Programa do Governo para a VIII Legislatura; 2011 2016)

"A água e o saneamento são ambos importantes para garantir a boa qualidade de vida, assim como para promover o desenvolvimento económico. Ampliar as infra-estruturas de água e o saneamento por todo o país é um objectivo do governo. O objectivo a longo prazo é ter 100 por cento de cobertura. Os projectos em curso serão alargados para aumentar a cobertura nacional e satisfazer todas as necessidades básicas como electricidade, água e saneamento. São objectivos para a VIII legislatura a construção das redes necessárias e o estabelecimento de um quadro institucional robusto, a fim de garantir o acesso e uma gestão adequada". (Programa do Governo para a VIII Legislatura; $2011-2016)$

Na comunidade de São Pedro em particular, carece ainda de saneamento básico, sistema de esgoto inexistente. A água canalizada que não chega a mais de $96 \%$ da população. E a saúde e educação também necessitam de uma especial atenção. Em relação a infra-estrutura de saúde, existe na comunidade uma Unidade Sanitária de Base, com um enfermeiro permanente, e, inicialmente ia quinzenalmente a essa comunidade um médico para consultas a população local. Actualmente nota-se a presença do médico uma vez por semana, quando não tem nenhuma urgência no Hospital da cidade do Mindelo, o que por vezes o impede de se deslocar a comunidade de São Pedro. E os serviços da protecção materno-infantil uma vez por mês, o que actualmente não cobre as necessidades locais dada ao aumento da taxa de natalidade.

O Governo tem elaborado politicas públicas direccionadas as comunidades rurais e litorais, mas ainda muito tem que ser feito para que o diálogo torne-se mais produtivo entre os as associações locais e o mesmo, e talvez mais real, executando tudo o que se escreve no papel. Muito se tem feito pelas comunidades piscatórias e rurais, mas ainda há um caminho longo a percorrer para a erradicação da pobreza a do desemprego. Essa possível articulação será analisada nos próximos capítulos.

\section{III-2.1. A construção das Politicas Públicas}

Em relação a elaboração dessas políticas públicas, não se verifica claramente, no programa do governo para a VIII Legislatura (2011-2016) , se elas foram concebidas de cima para baixo ou de baixo para cima, ou seja, se a população local participou de alguma forma da elaboração das políticas. Pelo programa do Governo que se teve como base para a elaboração desse mapeamento, fica-se com a visão de que são políticas elaboradas, com maior peso, pelo próprio governo, assim como algo poderia estar mais bem definido ou especificado. Parece-nos que todas estão descritas de forma global, para abranger realidades diferentes, como algo padronizado. Muitas das políticas estão expostas de uma forma muito geral, não especificando o que ira se fazer de concreto nas comunidades piscatórias, na medida em que essas localidades têm características específicas, mas também características semelhantes. 
Discutir políticas públicas requer fazer menção à relação Estado e Sociedade, na medida em que as políticas públicas correspondem à acção do Estado, ou seja, às respostas do Estado para as demandas da sociedade, tal como a educação a saúde, habitação, saneamento, entre outros aspectos para fazer face a necessidades e problemas enfrentados pela sociedade. Nesse sentido a participação da população local na elaboração e implementação de projectos poderá ajudar na formulação de políticas públicas na medida em que o saber local, o conhecimento local só vai ajudar na elaboração de projectos de acordo com a realidade da própria localidade ou comunidade.

Para tentar obter informações a cerca da construção das políticas públicas, contactamos o Gabinete do Primeiro Ministro/Centro de Políticas Estratégicas (GPM/CPE), a Autoridade Reguladora de Aquisição Pública (ARAP/CA/ADM), Ministério das Finanças e Planeamento (MFP/ADMIN), e não tendo um retorno por parte dos mesmos, após vários contactos feitos, a cerca de algumas questões que gostaríamos de colocar, para melhor entender como são elaboradas essas políticas públicas em Cabo Verde, ficaram as perguntas no ar. Das pessoas que trabalham nessas entidades que eu havia contactado, uma me respondeu que eu teria que me deslocar a cidade da Praia para obter as informações, outra disse para eu consultar o site caboverde2030 a onde não encontramos as nossas respostas, outros nem responderam.

\section{III.3 - Organizações Não Governamentais (ONG)}

De acordo com as duas associações locais, a comunitária e a de pescadores, um dos seus grandes parceiras são as Organizações Não Governamentais (ONG), por estarem constantemente a trabalhar no desenvolvimento da comunidade. Na comunidade de São Pedro destaca-se a ONG Atelier Mar, que esteve presenta na criação das duas associações acima referidas. Essas associações haviam solicitado assistência técnica na fase da sua organização. 0 Atelier Mar, uma das ONG cabo-verdianas de referência em desenvolvimento comunitário e economia solidária, com 34 anos de experiencia, tem trabalhado nas comunidades rurais e litorais nas Ilhas de São Vicente, Santo Antão, São Nicolau e Maio. Os objectivos da sua criação, é a erradicação da pobreza através da formação/capacitação e da promoção do desenvolvimento social e económico das comunidades rurais e litorais.

Em articulação com as associações locais, a referida ONG tem executado projecto, envolvendo directamente a população local, sendo que esta, através da exposição das suas necessidades, também contribuem para o desenvolvimento da sua comunidade.

\footnotetext{
"Gostaríamos de continuar a trabalhar com a ONG Atelier Mar porque acredito que eles podem nos ajudar com os nossos projectos na procura de financiamento e execução dos mesmos" (Associação N. G. Pescadores de São Pedro)

"O Atelier Mar é um bom parceiro que temos tido aqui na comunidade." (Fonte Associação Desenvolvimento Comunitário de São Pedro)
}

Tanto a Associação Nove Geração de Pescadores de São Pedro (ANGPSP) e a Associação de Desenvolvimento Comunitário (ADCSP), expõe a importância do trabalho que tem feito em parceria com a ONG, e mencionaram o desejo de continuar a trabalhar com a mesma. 
O desenvolvimento participativo deve dar voz a população local, quem melhor conhece a sua realidade, o que poderá contribuir por um melhor desenvolvimento local, através de ideias, iniciativas e alternativas de desenvolvimento. Apontará diferentes realidades e diferentes programas de desenvolvimento que poderão determinar e construir bases sólidas de desenvolvimento local.

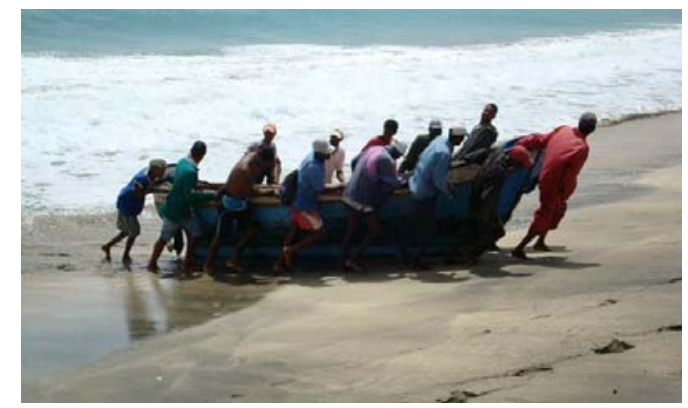

\section{INDICADORES DE DESENVOLVIMENTO ANALISADOS NA COMUNIDADE DE SÃO PEDRO}

Os indicadores de Desenvolvimento dão uma ideia concreta da evolução de uma determinada localidade, região ou cidade, no que se refere ao desenvolvimento económico, social e ambiental, demonstrando o que esses lugares tem ganho ou não ao longo dos anos. A análise desses indicadores na comunidade de São Pedro, objecto desta investigação, abarcam as valências sociais e económicas, como sejam, a educação, saúde, saneamento, comércio e turismo. Com base para a nossa análise valemo-nos do Relatório Documento Estratégico, Crescimento e Redução da Pobreza III (DECRP 2013) e do Programa do Governo para a VIII Legislatura, 2011-2016.

"Human Development is a process of enlarging people's choice. The most critical of these wide-ranging choices are to live a long and healthy life, to be educated and to have access to resources needed for a decent standard of living. Additional choices include political freedom, guaranteed human rights and personal self respect (UNDP, 1990a, p. 1)".

a. Capital natural (disponibilidade de recursos para agricultura, pesca, geografia, distancia do centro urbano, clima, etc)

A prática da agricultura é praticamente inexistente na comunidade, sendo que quem a pratica o faz para consumo próprio, ou seja para a subsistência familiar. Geralmente os produtos agrícolas consumidos na comunidade são comprados na cidade do Mindelo e são provenientes das localidades agrícolas da ilha de São Vicente e da Ilha de Santo Antão. Economicamente a agricultura não é expressiva na comunidade, em termos de geração de rendimentos.

Por seu lado a actividade pesqueira artesanal representa um importante capital para a comunidade de São Pedro, na medida em que todas as famílias da comunidade dependem dessa actividade, sendo que directa ou indirectamente 
todos tem familiares que exercem a actividade. Essa actividade representa um forte indicador de desenvolvimento para a comunidade, tanto a nível económico como social. Essa comunidade tem a ganhar com a dinâmica muito boa da associação de pescador local, na medida em que sempre esta a procura de melhorias no exercício da actividade pesqueira, apresentando suas ideias de projectos e procurando parcerias para implementação desses projectos.

Referente ao emprego em São Pedro, sendo uma comunidade cuja economia anda a volta da pesca, praticamente todas as famílias depende dos dividendos dessa actividade. Algumas mulheres que trabalham em fábricas nos arredores da cidade, ou mesmo na cidade do Mindelo, na venda de peixe abastecimento das mercearias da comunidade, em alguma instituição ou entidade. Muitos jovens queixam-se da falta de criação de oportunidades de emprego na comunidade. Segundo os dados do INE (Censo 2010), há um total de 991 pessoas residentes na comunidade de São Pedro, sendo 435 activos cuja idade esta acima dos 15.

\footnotetext{
"Pretende-se contribuir para o desenvolvimento económico, para a segurança alimentar e nutricional e para a melhoria do emprego, por via de uma gestão responsável que garanta a durabilidade na exploração dos recursos haliêuticos promovendo assim uma boa governação no sector." (Relatório DECRP III - Documento Estratégico, Crescimento e Redução da Pobreza (2013)
}

Um assunto que se tem vindo a falar muito nesses últimos tempos é o empreendedorismo, tendo como finalidade estimular a criatividade dos jovens, para o combate ao desemprego. Mas ainda, nas comunidades piscatórias há a necessidade de programas de informações e acções de sensibilização sistemáticos nesse sentido, para a procura de alternativas a pesca, como por exemplo incentivo a pequenos negócios de praia direccionados ao turismo.

b. Capital físico: (estradas, escolas, bens básicos das famílias, electricidade, água, saneamento, empresas, telefone, centro de saúde, etc)

Dá cidade do Mindelo até o Aeroporto Internacional, a estrada é asfaltada (cerca de 6Km), e do Aeroporto até a Comunidade de São Pedro a estrada é calcetada (cerca de $1 \mathrm{Km}$ ). Na localidade a maior parte das ruas ainda tem o piso de terra batida. Mas a Câmara Municipal de São Vicente tem nos seus planos de actividade o calcetamento das ruas da comunidade, embora sem data prevista para o seu início.

Como já havia referido, a comunidade tem uma escola de ensino básico que vai da 1a a 6a classe de escolaridade, e um jardim infantil. E em relação a saúde a comunidade tem uma unidade sanitária de base que actualmente muito pouco serve a comunidade devido a factores vários, tais como crescimento da população, a deslocação de idosos, etc. O servente ai permanente também esta capacitado para curativos ligeiros e aplicar injecções.

No que se refere ao saneamento, água canalizada e rede de esgoto, percorrendo a comunidade em estudo, São Pedro, sito na Ilha de São Vicente, ainda há muito que se fazer em relação a implementação desses itens, saneamento básico. Em pouquíssimas casas que possuem água canalizada, analisando os gráficos que obtive do inquérito. Segundo informações da Direcção do Ambiente A. e Equipamentos da Câmara Municipal de São Vicente, "não existe rede de esgoto em São Pedro, mas sim fossas que são construídas pelos moradores em suas casas. Quanto a água canalizada, 
não dispomos dessa informação por ser um serviço prestado pela Electra". A Electra confirmou-me que existe uma rede de água canalizada em São Pedro, mas ainda são poucos os que usufruem desse serviço.

\begin{abstract}
"A água e o saneamento são ambos importantes para garantir a boa qualidade de vida, assim como para promover o desenvolvimento económico. Ampliar as infra-estruturas de água e o saneamento por todo o país é um objectivo do governo. O objectivo a longo prazo é ter 100 por cento de cobertura. Os projectos em curso serão alargados para aumentar a cobertura nacional e satisfazer todas as necessidades básicas como electricidade, água e saneamento. São objectivos para a VIII legislatura a construção das redes necessárias e o estabelecimento de um quadro institucional robusto, a fim de garantir o acesso e uma gestão adequada". (Programa do Governo para a VIII Legislatura; $2011-2016)$
\end{abstract}

No entanto conseguimos informações referentes a água canalizada através do Instituto Nacional de Estatística, que se segue no gráfico abaixo, onde se nota que mais de $90 \%$ da população ainda não tem água canalizada na rede pública em casa. Abastecem de água através de carro autotanques, poços, chafarizes.

\begin{tabular}{|c|c|c|c|c|c|c|c|}
\cline { 2 - 7 } \multicolumn{1}{c|}{} & \multicolumn{9}{c|}{ Total } & & Água \\
\cline { 2 - 7 } & $\begin{array}{c}\text { Agregado } \\
\text { familiar } \\
\text { (Total) }\end{array}$ & $\begin{array}{c}\text { Água } \\
\text { canalizada } \\
\text { rede } \\
\text { pública } \\
\text { (poço, } \\
\text { levada, } \\
\text { canalizada, } \\
\text { na casa dos } \\
\text { vizinhos }\end{array}$ & Chafariz & Autotanque & nascente,..) & ND \\
\hline $\begin{array}{c}\text { SÃO } \\
\text { PEDRO }\end{array}$ & $\mathbf{2 0 3}$ &, 5 &, 0 & 65,5 & 30,5 & 3,0 &, 5 \\
\hline
\end{tabular}

Fonte: INE, Censo 2010

Referente a electricidade, segundo os dados do INE 2010, mais de 70\% da população tem electricidade em casa, segundo o gráfico abaixo.

\begin{tabular}{|l|r|r|r|r|r|r|r|}
\hline \multicolumn{1}{c|}{} & \multicolumn{9}{c|}{ Total } & & & \\
\cline { 2 - 8 } & $\begin{array}{c}\text { Agregado } \\
\text { familiar } \\
\text { (Total) }\end{array}$ & $\begin{array}{c}\text { Electricidade } \\
\text { rede pública }\end{array}$ & Vela & Petróleo & Gás & Outro & ND \\
\hline $\begin{array}{l}\text { SÃO } \\
\text { PEDRO }\end{array}$ & $\mathbf{2 0 3}$ & 79,8 & 6,9 & 11,3 &, 5 & 1,5 &, 0 \\
\hline
\end{tabular}

Fonte: INE, Censo 2010

\title{
c. Capital humano (condições de saúde, grau de educação de população, etc)
}

No que se refere a saúde com apenas um servente a unidade sanitária de base já não satisfaz a comunidade. A população local reivindica uma ambulância ou mesmo um médico presente na comunidade, cuja população cresce 
diariamente, o que acarreta a necessidade de um médico clinico geral e um pediatra, defende a população local. Uma vez por mês desloca-se a comunidade uma equipa dos serviços do PMI-PF para a vacinação das crianças. Quando se adoece há que se percorrer quilómetros até chegar a cidade.

Respeitante a educação, existe na comunidade um jardim infantil e uma escola de Ensino Básico Integrado (EBI), do 10 a 6o ano/classe. Após isso a crianças para continuar seus estudos desloca-se a cidade do Mindelo para este fim. Não existe na comunidade transporte escolar, apenas aqueles Toyota Hiace que fazem esse percurso várias vezes ao dia, transportando pessoas que vão a cidade por negócio, para consulta, para trabalho, para comprar produtos básicos abastecendo as mercearias da comunidade, entre outros aspectos.

População residente por zona, e Nível de Instrução

\begin{tabular}{|c|c|c|c|c|c|c|c|c|c|c|}
\hline \multirow[b]{2}{*}{ Zona } & \multirow[b]{2}{*}{ Sexo } & \multirow[b]{2}{*}{$\begin{array}{l}\text { População } \\
\text { residente }\end{array}$} & \multicolumn{7}{|c|}{ Nível de Instrução (3 ou mais anos de idade) } & \multirow{2}{*}{$\begin{array}{c}\text { Alfabetizad } \\
\text { os com } 15 \\
\text { anos ou } \\
\text { mais } \\
\end{array}$} \\
\hline & & & Sem nível & Pre-escolar & $\begin{array}{l}\text { Alfabetizaç } \\
\text { ão }\end{array}$ & $\begin{array}{l}\text { Ensino } \\
\text { Básico }\end{array}$ & Secundário & $\begin{array}{l}\text { Curso } \\
\text { Médio }\end{array}$ & $\begin{array}{c}\text { Bacharel. ou } \\
\text { Superior }\end{array}$ & \\
\hline \multirow{3}{*}{$\begin{array}{l}\text { SÃO } \\
\text { PEDRO }\end{array}$} & Total & 991 & 104 & 57 & 7 & 538 & 198 & 2 & 18 & 546 \\
\hline & Masculino & 513 & 43 & 28 & 3 & 303 & 99 & $\mathbf{0}$ & 6 & 296 \\
\hline & Feminino & 478 & 61 & 29 & 4 & 235 & 99 & 2 & 12 & 250 \\
\hline
\end{tabular}

Fonte: INE, Censo 2010

No ano de 2014 surgiu o primeiro hotel em São Pedro, investimento estrangeiro. É uma comunidade visitada por turistas, mas a população local tira pouco proveito dessas visitas de turistas. Provavelmente, por ainda não existir um espírito empreendedor na comunidade na medida em que existe na comunidade um artesanato local, aspectos culturais e gastronómicos que poderão ser uma mais-valia para São Pedro. Nesse sentido torna-se essencial a criação de condições para a promoção do turismo na comunidade.

A praia é muito boa para a prática do windsurf, e já acontecem campeonatos internacionais. É preciso nessa comunidade um turismo local bem planeado, trazendo o turista para o consumo na comunidade.

“...Serão desenvolvidos programas específicos para ligar as áreas rurais ao sector do turismo através da cadeia de valor e para promover o turismo rural e ecológico. A expansão do turismo às áreas rurais será feito através da promoção de linkages com as políticas e programas de habitação, permitindo aos pobres e aos habitantes das zonas rurais participar no turismo e noutros sectores da economia." (Programa do Governo para a VIII Legislatura; 2011 - 2016)

d. Capital social (confiança, solidariedade, entre ajuda, participação, colaboração, sentimento de valorização, cooperação)

O Capital Social é um conceito introduzido recentemente na área do desenvolvimento, na medida em que anteriormente o desenvolvimento não utilizava variáveis sociais em seus modelos. Por muito tempo o conceito de desenvolvimento esteve ligado ao viés de crescimento e ao âmbito global. Falava-se dos factores físicos, humanos, tecnológicos como sendo os únicos factores de desenvolvimento. Mas dado que a conjuntura globalização e os efeitos 
do liberalismo económico não aconteceram da mesma forma em todos os países, ou em todas as localidades, começou-se a pensar um desenvolvimento ligado ao cidadão local, surgindo assim o conceito de Capital Social.

Capital Social que contempla o económico, o social e o ambiental, assim como a cultura local. Passou-se a valorizar o individuo como sujeito capaz de participar no desenvolvimento local, e esses ao tomarem consciência de que as mudanças na sua localidade podem ser direccionadas de acordo com seus interesses, Ihes vai despertar o interesse para criarem condições e promoverem o desenvolvimento da sua localidade. Nesse sentido os indivíduos de determinada localidade vão direccionar os seus esforços para o trabalho colectivo, no sentido de haver cooperação entre os actores.

O capital social passou assim a ser reconhecido e introduzido no pensamento económico sobre o desenvolvimento. Sendo que o desenvolvimento de uma comunidade não é atribuição exclusiva do Estado, Organismos ou de instituições a maior contribuição para melhorias e o desenvolvimento local é o engajamento da comunidade cívica. Assim, a solidificação da democracia buscando melhores condições de vida para os cidadãos e um desenvolvimento adequado e sustentável faz com que o envolvimento da população local torna-se essencial, fortalecendo o capital social (Putnam. 1995).

\section{V - CONSIDERAÇÕES FINAIS}

Uma das primeiras conclusões, é o facto de que a existência e intervenção da associação local torna-se primordial para que a comunidade seja ouvida pelas Entidades, Organismos e ONG, nacionais e internacionais. Bem organizadas e funcionais, essas associações são uma mais-valia para a comunidade de São Pedro, levando ao conhecimento das entidades competentes e das ONG, as necessidades e problemas a serem resolvidos na comunidade, através de projectos por eles próprios elaborados, ou com a ajuda de alguma ONG.

Adaptar-se a realidade local, a cultura local, poderá e pode ser uma mais-valia para o desenvolvimento da comunidade. Aliar o local ao global de forma sustentável, permitindo assim criar bases sólidas não só ao desenvolvimento local, mas também ao desenvolvimento do país.

Em relação as políticas públicas, existem na documentação do programa do governo, para as zonas ou localidade rurais e litorais, mas não se vê claramente se são elaboradas com subsídios advindos da população local, ou não. A princípio são descritas de forma geral, para serem adaptadas a cada realidade local.

Entende-se que em Cabo Verde, pelo facto de ser um país em vias de desenvolvimento, existem muitas dificuldades para abranger o desenvolvimento em todas as ilhas, principalmente nas comunidades rurais e litorais. Daí a importância, das associações de desenvolvimento nas pequenas comunidades, para melhor articulação entre as mesmas com outras ONG, organismos e entidades, no sentido de se promover o desenvolvimento das mesmas.

A participação da população local realça as necessidades e problemas da comunidade o que vai contribuir para uma melhor resolução dos problemas, ou seja valorizar o conhecimento local, conhecimento endógeno, como algo pertinente ao desenvolvimento. Essas associações atraem ONG nacionais e internacionais, agências de Cooperações Internacionais, e outros organismos, permitindo assim o desenvolvimento local. 
A comunidade de São Pedro ainda não beneficia das políticas públicas descritas no programa do Governo, como seja o caso do saneamento básico, esgoto e água canalizada.

No entanto, verifica-se que as associações locais, as ONG e agências de desenvolvimento e de cooperação formam parcerias funcionais que evidenciam resultados positivos durante a execução de alguns projectos na comunidade. Provavelmente por serem pessoas que se deslocam ao terreno para, juntamente com a associação local, identificarem as necessidades e os problemas locais. Nota-se que as ONG, cooperação internacional instituições estão sempre em contacto com as associações local, bem como com a população da comunidade.

Quanto à Câmara Municipal, constatamos algumas realizações pontuais, como sejam a construção de habitações sociais ou a ajuda financeira a alunos para prosseguirem os estudos na cidade do Mindelo. No entanto, consideramos que é preciso fazer muito mais, casos de uma rede de esgoto, um polidesportivo, o calcetamento das ruas, de entre outros aspectos que poderão criar condições ao desenvolvimento em São Pedro, dinamizando a economia local.

Quanto aos indicadores de desenvolvimento, é nossa percepção, que a comunidade tem poucas infraestruturas e investimentos que promovam um desenvolvimento adequado da mesma. Ainda há muito que se fazer em São Pedro a nível da saúde, do emprego, da segurança, do turismo, do saneamento básico, de entre outros aspectos.

Também actualmente já se sente a necessidade de um posto policial na comunidade, por esta ser muito frequentada por pessoas de fora da comunidade, acontecendo por vezes algum distúrbio. Cabo verde deve continuar a apoiar as organizações sociais nas comunidades piscatórias e rurais, sendo que estas podem ajudar o próprio governo na identificação de necessidades básicas para o desenvolvimento local, e criar bases sustentáveis que permitam a redução da pobreza e promover uma melhor qualidade de vida local. Que as pequenas localidades rurais e piscatórias tenham meios para se sustentarem e estarem inseridos no processo de desenvolvimento minimizando, reduzindo ou mesmo travando, assim a pobreza. Um país que promova o desenvolvimento com base local sustentável tem melhores possibilidades de enfrentar a globalização e a concorrência dos mercados globais

\section{Referências}

AMARTYA Sen. (2001) Desenvolvimento como liberdade. Editora SCHWARCZ Ltda,

BUARQUE, Sérgio C. Construindo o desenvolvimento local sustentável - Metodologia de Planejamento. 2002.

CABRAL, José Carlos de Pina - O Papel do turismo no desenvolvimento de Cabo Verde: Turismo e combate à pobreza, pág. 26

CHALLINOR, Elizabeth. O silêncio e as palavras: Reflexões à volta da participação e do poder na promoção do associativismo em Cabo Verde. P.97.115.

Cruz, lolanda. Dissertação de Mestrado: Políticas de Desenvolvimento, ONG, Participação e Desenvolvimento Local: estratégias articuladas para o desenvolvimento da comunidade piscatória de São Pedro - Ilha de São Vicente. 2012 2014. 
ESCOBAR, Arturo. El “postdesarrollo" como concepto y práctica social, IN: Imaginando un futuro: Pensamiento crítico, desarrollo y movimientos sociales. En Margarita López Maya (ed.), Desarrollo y democracia. 1991, Caracas: Universidad Central de Venezuela y UNESCO, pp. 135-170.

ESCOBAR, Arturo. Antropologia Y Desarrollo. Disponível em: http://www.humanas.unal.edu.co/colantrpos/Antrpologia y desarrollo AEscobar.pdf

ESCOBAR, Arturo. Anthropology and the Development Encounter: The making and marketing of Development Anthropology. 1991, Américan Ethnologist, 18(4): 658 -682.

FRIEDMAN, John. Empowerment uma Política de Desenvolvimento Alternativo. Lisboa: Celta. 1996

FRIEDMAN, John. Empowerment uma Política de Desenvolvimento Alternativo. Lisboa: Celta. 1996. IN: CHALLINOR, Elizabeth. O Silencio e as Palavras: Reflexões à volta da Participação e do Poder na promoção do Associativismo em Cabo Verde. (p.97-115)

GENTILLI, Raquel. Representações e práticas. SP: Veras; 2006. apud: WELLINGTON Trotta. POLITICA SOCIAL: PERSPECTIVA DE MEDIDAS EFETIVAMENTE. Disponível em: www.achegas.net/numero/43/Wellington 43.pdf

MARTINE, George. O lugar no espaço na equação população meio ambiente. R. bras. Est. Pop., São Paulo, v. 24, n. 2 , p. 181-190, jul./dez. 2007

MOHAN, Giles. Participatory Development. In: Desai, Vandana and Potter, Rob eds. The Arnold companion to development studies. London, UK: Hodder, pp. 49-54.

OLIVEIRA, Gilson. Revista FAE, Curitiba, v.5, n.2, p.37-48, maio/agosto. 2002

PLATAFORMA DAS ONG'S. Enquadramento Jurídico das ONG's em Cabo Verde. Fevereiro de 1999

PROGRAMA DO GOVERNO para a VIII Legislatura (2011-2016).

ROSTOW, W. Etapas do Desenvolvimento Económico, (1961).

SHISHITO, Akira Fábio. Análise do conceito de Desenvolvimento Humano utilizado pelo PNUD/ONU: Raízes e Desenvolvimentos.<http://www.pnud.org.br> acesso em 23 de novembro de 2013.

TEIXEIRA, Elenaldo Celso. O papel das Políticas Públicas no Desenvolvimento Local e na Transformação da realidade; 2002.

WELLINGTON Trotta. POLÍTICA SOCIAL: PERSPECTIVA DE MEDIDAS EFETIVAMENTE. Disponível em: www.achegas.net/numero/43/Wellington 43.pdf

PÚBLICAS. O autor professor universitário, bacharel em Direito (UGF) e em Filosofia (UERJ), Mestre em Ciência Política (IFCS-UFRJ) e Doutorando em Filosofia (IFCS-UFRJ). 